Regards sur l'économie allemande

Bulletin économique du CIRAC

$118-119 \mid 2015$

Varia

\title{
Budgets : excédent malgré l'effort pour les réfugiés
}

Isabelle Bourgeois

\section{OpenEdition}

Journals

Édition électronique

URL : http://journals.openedition.org/rea/4898

DOI : $10.4000 /$ rea.4898

ISSN : 1965-0787

Éditeur

CIRAC

Édition imprimée

Date de publication : 31 décembre 2015

Pagination : 37-38

ISSN : 1156-8992

\section{Référence électronique}

Isabelle Bourgeois, « Budgets : excédent malgré l'effort pour les réfugiés 》, Regards sur l'économie allemande [En ligne], 118-119 | décembre 2015, mis en ligne le 31 décembre 2017, consulté le 15 septembre 2020. URL : http://journals.openedition.org/rea/4898

Ce document a été généré automatiquement le 15 septembre 2020.

(c) CIRAC 


\title{
Budgets : excédent malgré l'effort pour les réfugiés
}

\author{
Isabelle Bourgeois
}

1 Le cap de consolidation budgétaire de l'Allemagne ne sera pas remis en question par le coût lié à l'accueil des réfugiés. Certes, il se traduira par une hausse des dépenses publiques notamment en matière de prestations sociales en espèces ou en rémunération des salariés du public (les embauches se multiplient pour assurer l'accueil des réfugiés). Mais comme, dans l'ensemble, l'encours des recettes fiscales et des prélèvements sociaux augmente sous l'effet du quasi-plein-emploi, de la dynamique de l'activité et de la bonne tenue de la consommation, le solde budgétaire devrait rester excédentaire. Telle est du moins l'hypothèse du Conseil des Sages dont il souligne qu'elle reste entachée d'incertitudes face à la grande inconnue du nombre de réfugiés qui arriveront en Allemagne l'an prochain.

Recettes et dépenses publiques prévisionnelles de la RFA 2015 et 2016

\begin{tabular}{|c|c|c|c|c|c|}
\hline & 2014 & $2015 P$ & $2016 P$ & $2015 P$ & $2016 P$ \\
\hline & \multicolumn{3}{|c|}{ en milliards $€$} & évol. 2015/14 & évol. 2015/16 \\
\hline Recettes & 1299,6 & 1345,2 & 1381,3 & $3,5 \%$ & $2,7 \%$ \\
\hline Recettes fiscales & 659,6 & 687,7 & 702,4 & $4,3 \%$ & $2,1 \%$ \\
\hline Prélèvements sociaux & 481,9 & 500,6 & 517,6 & $3,9 \%$ & $3,4 \%$ \\
\hline Autres & 158,1 & 156,9 & 161,3 & $-0,8 \%$ & $2,8 \%$ \\
\hline Dépenses & 1290,7 & 1324,0 & 1375,8 & $2,6 \%$ & $3,9 \%$ \\
\hline Consommations intermédiaires & 138,6 & 143,6 & 149,9 & $3,7 \%$ & $4,4 \%$ \\
\hline
\end{tabular}




\begin{tabular}{|c|c|c|c|c|c|}
\hline Rémunération des salariés & 224,6 & 230,5 & 237,4 & $2,6 \%$ & $3,0 \%$ \\
\hline Service de la dette & 51,5 & 47,4 & 44,4 & $-7,9 \%$ & $-6,4 \%$ \\
\hline Subventions & 25,5 & 26,4 & 27,0 & $3,7 \%$ & $2,3 \%$ \\
\hline Prestations sociales en espèces & 451,0 & 471,1 & 489,1 & $4,5 \%$ & $3,8 \%$ \\
\hline Prestations sociales en nature & 240,1 & 252,8 & 266,0 & $5,3 \%$ & $5,2 \%$ \\
\hline Investissements bruts & 63,2 & 64,3 & 68,2 & $1,6 \%$ & $6,0 \%$ \\
\hline Autres & 96,2 & 87,8 & 93,8 & $-8,7 \%$ & $6,8 \%$ \\
\hline Solde budgétaire & 8,9 & 21,2 & 5,5 & - & - \\
\hline Chiffres clés & \multicolumn{5}{|c|}{ en $\%$} \\
\hline Dépenses publiques & 44,3 & 43,7 & 44,0 & - & - \\
\hline Consommation publique & 19,3 & 19,4 & 19,6 & - & - \\
\hline Prélèvements sociaux & 15,4 & 15,4 & 15,4 & - & - \\
\hline Prélèvements obligatoires & 38,3 & 38,5 & 38,1 & - & - \\
\hline Déficit & 0,3 & 0,7 & 0,2 & - & - \\
\hline Déficit structurel & 0,5 & 0,3 & 0,1 & - & - \\
\hline Ratio dette publique/PIB & 74,9 & 70,8 & 67,8 & - & - \\
\hline Intérêts de la dette en \% des recettes & 7,7 & 6,8 & 6,3 & - & - \\
\hline
\end{tabular}

Source : Sachverständigenrat zur Begutachtung der gesamtwirtschaftlichen Entwicklung, Jahresgutachten 2015/16, page 111.

\section{Priorité malgré tout à la rigueur}

Cela étant, l'excédent budgétaire de 2015 s'explique aussi par des recettes exceptionnelles : 8 milliards $€$ proviennent de la restitution du produit de certains impôts (IS ou taxe sur les activités industrielles et commerciales) à la suite de plusieurs arrêts de la Cour fédérale des finances, 5 milliards $€$ de la vente aux enchères de fréquences de téléphonie mobile. En regard, les dépenses augmentent elles aussi, sous l'effet de la hausse des investissements publics et des récentes mesures abaissant l'âge légal de départ à la retraite à 63 ans pour ceux qui ont cotisé 45 ans, revalorisant le montant des pensions en 2016 ou augmentant les prestations de l'assurance dépendance. Mais le Conseil des Sages met en garde contre toute tentation de redistribution : en effet, en 2015 , «les recettes supplémentaires sont déjà pour l'essentiel budgétisées dans la colonne dépenses ». Or celles-ci sont en hausse. 
INDEX

Mots-clés : budget, réfugiés, rigueur 